physical (and particularly the structural) characterisation of minerals. To what extent does the second edition reflect these changes, and will it be as useful a servant to the mineralogists of the 1980s as the first edition was to those of the 1970s?

The list of contents of the second edition is little changed, two chapters (on automatic image analysis and neutron activation analysis) having been added, and one (on optical emission spectroscopy) deleted. The remaining chapters have been revised, sometimes by new authors. The extent of this revision may be judged by the increase in the proportion of new references, which ranges from about $20 \%$ for subjects such as mineral separation which have seen slow progress to $75 \%$ for those such as electron diffraction in which progress over the past 11 years has been very rapid.

A more detailed inspection of the revised chapters reveals particularly important changes in those dealing with reflected light miscroscopy, where quantitative reflectance measurements have increased in importance; with electron probe microanalysis, which has been affected by the introduction of energydispersive detectors; and with electron

\section{Plant molecular biology}

Molecular Biology of Plant Cells. Edited by H. Smith. Pp. 496. (Blackwell Scientific: Oxford, 1978.) £13.50.

IN the preface to this book the editor draws attention to the emerging enthusiasm and additional funding for basic research in plant biochemistry, cell physiology and genetics. This, he concludes, emphasises the need "for the training of competent research workers with specialist knowledge of plant cells, their structure, function, biochemistry and genetics". This book has been written with this kind of training in mind.

The seventecn chapters are divided into three major sections: "Plant Cell Siructure and Function" (2 $i 5$ pages), "Gene Expression and its Regulation in Plant Cells" (178 pages), and thc "Manipulation of Plant Cells" (48 pages). That some effort has becn made to introduce a measure of uniformity into the way each of the chapters has; been written is very evident. For example, in the first section each of the chapters has a brief introduction followed by descriptions of the struc. ture of the particular cell components and their constitutent molecules followed by discussions on functions and mechanisms. Many but not all the microscopy. There are useful improvements in most of the remaining chapters.

The new chapters, on image analysis and neutron activation analysis, will be of interest to many workers in both pure and applied mineralogy, and both techniques are likely to increase in importance during the currency of this edition. Both contributions are clear and well written.

With the increasing importance of physical methods of characterising minerals, a trend likely to continue during the life of this edition, it is a pity that more attention was not devoted to such subjects as modern single-crystal diffraction methods, including neutron diffraction. Despite this omission, the new edition undoubtedly represents a useful addition to the literature. The price is reasonable, but probably still high enough to deter individuals who own the first edition from buying the second. Libraries serving materials scientists concerned with minerals should not be so deterred, for there is much new material in the book.

R. G. J. Strens

R. G.J. Strens is a mineralogist working at the Institute of Lunar and Planetary Sciences, University of Newcastle upon Tyne, UK.

chapters have a short summary.

Texts on plant biochemistry all too often fail to emphasise adequately the relationships between molecular structure and function. This is not one of them. Most, if not all, the authors of this book have paid particular attention to this important point.

Two chapters are devoted to membranes. One focuses on current models of membrane structure and how different kinds of molecules pass through them. but the second has, more unexpectedly, been included to emphasise the three-dimentional organisation and relationships of different membranes and the role endomembranes play in building the plant cell and integrating cellular activities. The inclusion of these chapters highlighting membrane functions is especially valuable, as current very interesting models of membranes as the primary action sites of auxin, gibberellic acid and phytochrome are introduced in other chapters devoted to the structures, functions and mechanisms of action of hormones and phytochrome.

To many molecular biologists, the lack of evidence in the text for the use of genetic variation in establishing relationships betwen structure, function and control mechanisms will be disturbing. This reflects the state of plant genetics, biochemistry and physiology rather than deficiencies in this particular book. The section on gene expression and its regulation opens with a brief sketch of the Jacob-Monod model for gene control in prokaryotes. This appearance of the details of prokaryotic gene control will probably serve to perpetuate erroneously the idea that the genes of higher plant are controlled in a similar way. Studies on fungi, which could have been more usefully highlighted, provide only little support for the relevance of the prokaryotic model for gene control in eukaryotes. Furthermore, there is ample evidence in the 178 pages of the second section on "Gene Expression and its Regulation" (covering the nucleus, protein synthesis, the regulation of enzyme levels and activity, hormone and phytochrome action) that hardly anything is known about gene control at the DNA level in higher plants.

As would be expected for a book on plant biochemistry, considerable space is devo ed to chloroplasts. Two chapters ("Chloroplasts-Structure and Developmen $\imath$ ", and "Chloroplasts-Structure and Photosynthesis") are included in the first scction of the book, and a chapter on "The Genetic Information of Organelles and its Expression" is included in the second section. Together these chapters provide a good account of our knowledge of chloroplasts. Again their metabolic relationships to and dependence on other parts of the cell have not been neglected.

The final section of the book introduces that area of botanical research that surely has considerable promise for molecular biology-the culture of plant cells, protoplasts and the regeneration of whole plants from them. The exploitation of these systems in plant molecular biology has hardly begun. This is obvious from these chapters themselves and also from the paucity of information derived from cell cultures included in the other sections of the book.

I found the whole book very worthwhile reading. However, at $£ 13.50$, I suspect few undergraduates or research students will purchase it. This will perhaps be the biggest deterrent to it fulfilling its aims. Another serious difficulty with textbooks of this kind is their inevitable failure to be up to date. The emerging increased enthusiasm and additional funding for plant molecular biology has produced, in the past year or two, results which should be in a book of this kind. For example, the physical mapping of genes within the organelle genomes using restriction endonucleases is not mentioned, yet this approach and its natural developments will undoubtedly contribute considerably to plant molecular biology over the useful lifetime of this edition.

Richard B. Flavell

Richard B. Flavell is Principal Scientific Officer in the Cytogenetics Department of the Plant Breeding Institute, Cambridge, $U K$. 